Azimi, H., H. Mousavi-Sabet and S. Eagderi 2015.Osteology of Hyrcanian Crested Loach, Paracobitis hircanica (Pisces, Nemacheilidae). Our Nature 13(1): 8-18. DOI: http://dx.doi.org/10.3126/on.v13i1.14203

\title{
Osteology of Hyrcanian crested loach, Paracobitis hircanica (Pisces, Nemacheilidae)
}

\author{
H. Azimi ${ }^{1}$, H. Mousavi-Sabet ${ }^{*}$ and S. Eagderi ${ }^{2}$ \\ ${ }^{1}$ Department of Fisheries, Faculty of Natural Resources, University of Guilan, Sowmeh Sara, P.O. Box 1144, \\ Guilan, Iran \\ ${ }^{2}$ Department of Fisheries, Faculty of Natural Resources, University of Tehran, P.O. Box 4314, Karaj, Iran \\ *E-mail:mousavi-sabet@guilan.ac.ir/mosavii.h@gmail.com
}

Received: 23.09.2013; Accepted: 14.09.2014

\begin{abstract}
This study was carried out to describe of osteological structure of the newly described crested loach, Paracobitis hircanica Mousavi-Sabet et al., 2015. For this purpose, ten specimens were collected from the Zaringol River, in the southeastern Caspian Sea basin. After clearing and staining, osteologicl characteristics were examined. The obtained results showed that the $P$. hircanica is osteologicaly characterized by plate-like protrusion in epibranchial-4, no sesamoid ossifications, five hypurals, free and long epural, no connection between retroarcticulare and dental, loss of preethmoideum-I and basibranciale-4, alveolar bony capsule and presence of the manubrium.
\end{abstract}

Key words: Fish skeleton, Manubrium, Epural, Caspian Sea basin, Iran

\section{Introduction}

Family Nemacheilidae has the greatest diversity in Iranian fresh waters after Cyprinindae (Nelson, 2006; JouladehRoudbar et al., 2015). The loaches with a longdorsal dermal crest have been placed in the genus Paracobitis Bleeker, 1863 for many years, specifically those from Central Asia (Banarescu and Nalbant, 1964), Vietnam (Nguyen, 2005), the Middle East (Prokofiev, 2009) and China (Min et al., 2010). The genus Paracobitis was appointed by Bleeker (1863) for Cobitis malapterura. This genus is restricted to Near East and Middle Asia, and the species of Paracobitis from China should be assigned to the genera Homatula and Schistura (Nalbant and Bianco, 1998). The species of the genus Paracobitis are comparatively large-sized loaches inhabi- ting freshwaters of western Asia (Bănărescu and Nalbant, 1995; Nalbant and Bianco, 1998). There are fourteen valid species in the world, which ten valid species are reported from Iran with four others in the adjusted countries (Kottelat, 2012; Coad, 2014; Mousavi-Sabet et al., 2014; Freyhof et al., 2014). According to Freyhof et al (2014) and Mousavi-Sabet et al., (2015), the valid Paracobitis species in Iran comprises, $P$. atrakensis Esmaeili et al. 2014, $P$. basharensis Freyhof et al., 2014, $P$. hircanica Mousavi-Sabet et al., 2015 P. longicauda Kessler, 1872, P. malapterura (Valenciennes, 1846), P. molavii Freyhof et al., 2014, P. persa Freyhof et al., 2014, P. rhadinaea (Regan, 1906), P. smithi (Greenwood, 1976) and P. vignai Nalbant and Bianco, 1998. Paracobitis hircanica, 
distributed in the southeastern Caspian Sea basin in the Zaringol River (Mousavi-Sabet et al., 2015). As the species is recently described based on morphological characters, therefore, the present study was conducted to provide a detailed osteological characteristics of this species. Thus, the results of this study can be used as a reference for comparison with the other Paracobitis species.

\section{Materials and methods}

Ten specimens of Paracobitis hircanica (Fig. 1) with standard lengths of 54.4-62.5 $\mathrm{mm}$ were collected by electrofishing from the Zaringol River, in the southeastern Caspian Sea basin, located in Golestan Province, north of Iran. The collected specimens were anesthetized in $1 \%$ clove solution and then fixed in $5 \%$ buffered formalin. For osteological examination, the specimens were cleared and stained with alizarin red $\mathrm{S}$ and alcian blue based on Taylor and Van Dyke (1985). The skeletal structures were dissected and photographed using scanner (Epson v600) equipped with a glycerol bath. The skeletal structure of specimens were observed and studied by a Leica MS5 stereomicroscope. The obtained images were drawn using CorelDrawX6 software. Nomenclature and abbreviation of the skeletal elements were done according to Prokofiev (2009).

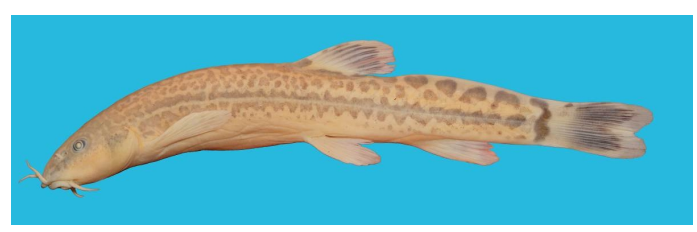

Figure 1. Paracobitis hircanica, $95 \mathrm{~mm} \mathrm{SL}$, collected from the Zaringol River, southeastern Caspian Sea basin Iran.

\section{Results \\ Neurocranium}

The anterior part of the neurocranium is narrower and the posterior part is wide and oval-shaped. The maximum width of the skull is at the level of the pterotic edge. The ethmoid region comprises of the paired lateral ethmoid and, unpaired prevomer and supraethmoid-ethmoid (Fig. 2a). The supraethmoid-ethmoid is vertically fused to the prevomer and posteriorly connected to the frontal (Fig. 2a). In anterior part of the neurocranium, the paired L-shaped lateral ethmoids are present. The posterior part of the lateral ethmoid forms the anterior part of orbit. The prevomer is a flattened bone with the rounded edges anterolaterally. Also, the prevomer is connected to the orbitosphenoid and parasphenoid posteriorly (Fig. 2b). There is no preethmoid-I. The paired preethmoid-II and prepalatine, and unpaired Kinethmoid are connected to the ethmoid region of neurocranium. The preethmoid-II is short and cylindrical, slightly curved from middle side, and flattened at two ends. From latero-external part, the preethmoid-II is connected to the prepalatine. Also, this bone attached to the anterior edge of the prevomer and maxilla from the posteriorly and anteriorly, respectively. The kinethmoid is a small and free bone situated between two maxilla bones vertically (Fig. 3b).

The orbital region includes the frontal, orbitosphenoid, pterosphenoid, parasphenoid, and sclerotic bones. The paired frontals are largest elements of the skull roof (Fig. 2a). These bones involve about half of the length of the neurocranium separating by fontanel posteriorly. The posterior margins of the frontals are also involved in formation of the fontanel. Also, the frontal is connected to the orbitosphenoid anterolaterally (Fig. 2b). 


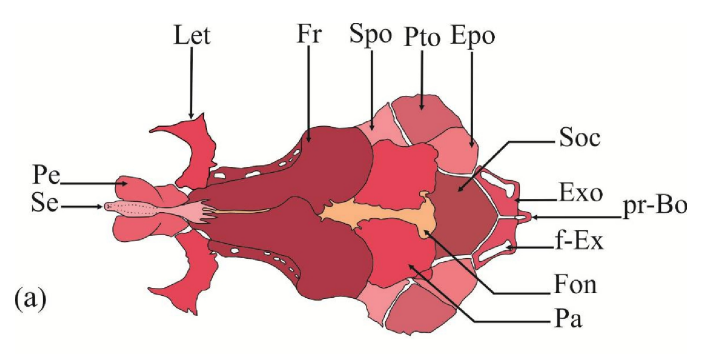

(b)

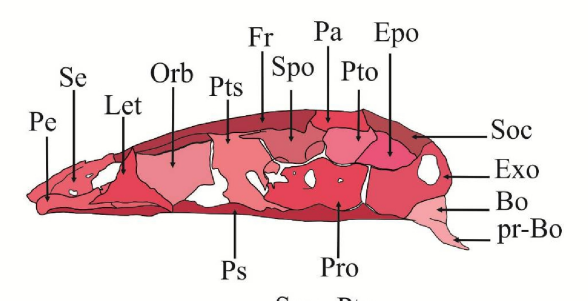

(c)

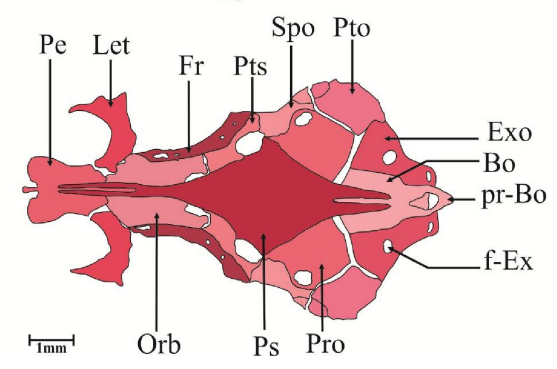

Figure 2. The neurocranium of Paracobitis hircanica. a) Dorsal b) lateral, c) ventral view; fon: fontanel; frExo: foramen exoccipital; pr-Bo: basioccipital process; Bo: basioccipital; Epo: epiotic; Exo: exoccipita; Fr: frontal; Let: lateral ethmoid; Orb: orbitosphenoid; Pa: parietal; Pe: prevomer; Pro: prootic; Ps: parasphenoid; Pto: pterotic; Pts: pterosphenoi; Se: supraethmoid-ethmoid; Soc: supraoccipital; Spo: sphenotic.

The pterosphenoid is connected to the frontal and sphenoid in the dorsal and posterolateral margin, respectively, which forming the posterior part of the orbit. The posterior margin of pterosphenoid is curved, creating a cavity with prootic and parasphenoid bones (Fig. 2c). The parasphenoid is the largest bone in the base of the neurocranium. This bone is extended from the prevomer to the basioccipital and bifurcated at two ends. The otic region comprises of the parietal, sphenotic, pterotic, prootic, and epiotic (Fig. 2). The parietal is approximately square-shaped and anteriorly connected to the frontal. The posterior margin of this bone is connected to the supraoccepital and epiotic and its lateral margin is connected to the pterotic and sphenotic. Also, these paired bones are separated by fontanel (Fig. 2a). The pterotic is quarter-circle in shape and connected to the epiotic and sphenotic dorsolaterally and to the prootic and exoccipital venterolaterally (Figs. 2a, 2c). The sphenotic is at the end of orbit, creating lateral wall of the neurocranium (Fig. 2b). The sphenotic is connected to the prootic ventrally and to the parietal posterodorsally. The paired prootic are the largest bones of the skull base (Fig. 2c). These paired bones are connected to each other in the lateroposteriorly. The paired epiotics are the most posterior bones of the otic region, and connected to the supraoccipital and pterotic laterally (Fig. 2c). The occipital region comprises of the exoccipital, supraoccepital, and basioccipital bones. The supraoccipital is pentagon-like bone, which anterior margin is involved in the formation fontanel. In addition, this bone is connected to the paired exoccipitals and fontanel from the dorsal and anterior parts, respectively. The exoccipital has a large lateral foramen (for. lateralis exoccipitalis). The basioccipital bone has a ring-shaped process posteriorly (pr. basioccipitalis) located between two exoccipitals bones (Fig. 2c). In the lateral surface of the neurocranium, there are two facets for the articulation with the heads of the hyomandibular. The anterior facet is formed by the pterosphenoid, sphenotic and prootic; and the posterior one by the sphenotic and pterotic. The skull roof has an opening viz. fontanel which is covered by 


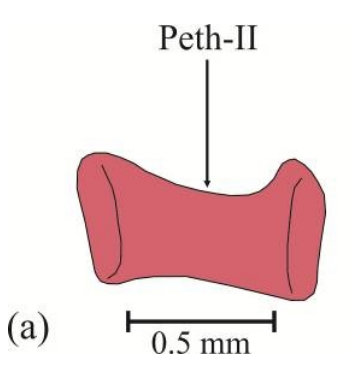

(b)

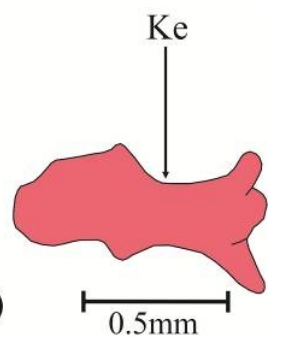

Figure 3. Preethmoid-II (a) and Kinethmoid (b) bones of Paracobitis hircanica; Ke: kinethmoid; Peth: preethmoid.

connective tissue and extended longitudenally (Fig. 2a). Also the fontanel is surrounded by parietal, frontal, and supraoccipital bones.

\section{Jaws}

The upper jaw consists of the premaxilla and maxilla (Fig. 4a). The premaxilla is thin Lshaped bone and possesses a narrow vertical process, i.e. pr. Ascenden, and curved horizontal process, i.e. pr. Alveolar. The maxilla is a large laminar bone that has two narrow and wide sections at the anterior and posterior ends. Also, the maxilla is connected to the prepalatine and preet-hmoid-II. The lower jaw is composed of the dental, articular, retroarticular and crono-meckelian (Fig. 4a, $4 \mathrm{~b})$. The dental is the largest bone of this series and possesses two parts, including narrow ramus dentalis and a wide coronoid process. This bone is connected to the articular and retroarticular bones posteriorly. The articular is connected to the dental, retroarticular, and quadrate, respectively, anteriorly, ventrally, and posteriorly. The subtriangular coronomec-kelian is present on the internal side of the lower jaw situated in dorsal part of articular bone.

\section{Suspensorium}

The suspensorium comprises of the autopalatine, endopterygoid, ectopterygoid, metaptrygoid, quadrate, symplectic and hyomandibular (Fig. 5). The autopalatine processes a V-shaped depression in the middle section which is attached to the prevomer and connected the branchiocranium to the anterior part of neurocranum. Also, the autopalatine is jointed to the endoptrygoid posteriorly and prepalatine and preethmoid-II anteriorly. The endoptrygoid is connected to the metaptrygoid and ectoptrygoid ventrally and to the autopalatine by a condyle anteriorly. Also, there is a bulge in the middle-dorsal section of this bone. The ectoptrygoid bears a pointed process in the anteroventral part and situated between quadrate and endoptrygoid bones. The metaptrygoid is a roughly trapezoid bone which is situated between the hyomandibular and quadrate bones. The anterior section of this bone is wider than the posterior part. The quadrate has a pointed and stretched abdominal process which is leaned to back. There is also a smaller process in the anterior margin of this bone that is leaned forward (Fig. 5). This bone is connected to the endoptrygoid and metaptrygoid dorsally and posteriorly, respectively. The symplectic is almost triangular bone that located between the quadrate and hyomandibular bones anteriorly and posteriorly, respectively. The anterior part of this bone is narrow and wider posteriorly. The hyomandibular is a relatively large extending longitudinally and its dorsal part is wider than its ventral one. There are two condyles on dorsal margin of the hyomandibular which are articulated to the neurocranium. Also, in the posterior margin of this bone, the operclar condyle 
(a)

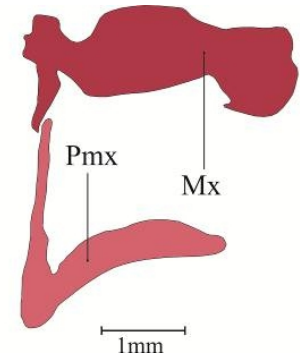

(b)

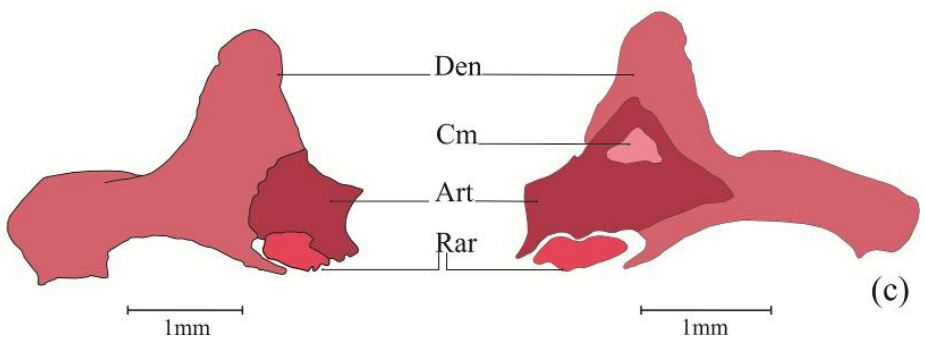

Figure 4. (a) Upper jaw, (b) lateral view of lower jaw and (c) medial view of lower jaw in Paracobitis hircanica. Art: articular; Cm: coronomeckelian; Den: dental; Mx: Maxilla; Pmx: Premaxilla; Rar: retroarticular.

exists. The prepalatine is a small bone which jointed to the preethmoid-II and maxilla, respectively, in the dorsal margin and anterior part.

\section{Opercular series}

The operclular series includes opercle, preopercle, subopercle, and interopercle (Fig. 5). The opercle is a largest and triangular-shaped bone of this set which has

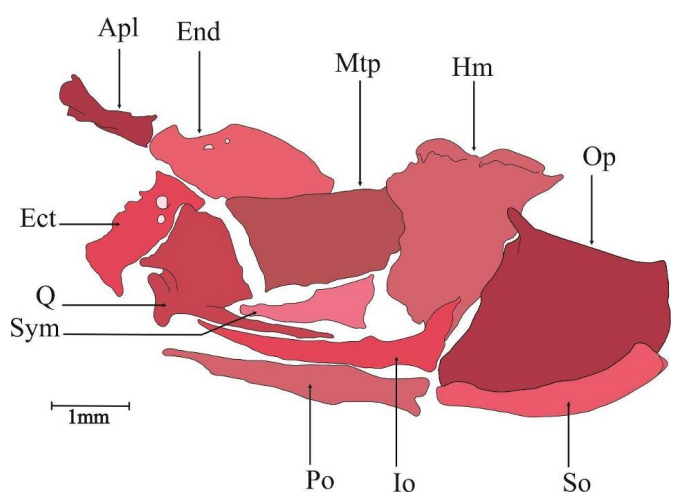

Figure 5. Lateral view of suspensorium and opercle series of Paracobitis hircanica. Ect: ectopterygoid; End: endopterygoid; Hm: hyomandibulare; Io: interopercle; Mtp: metapterygoid; Op: opercle; Po: praeopercle; Q: quadrate; So: subopercle; Sym: symplecic.

a rod-shaped process anterodorsally for connection to the operculi levator muscle. The ventral margin of opercle is connected to the subopercle that is narrow and striplike. The interopercle is a narrow and stretched bone which the anterior section of this bone is pointed and wider in the posterior part. The preopercle is a straight bone and its posterior part bears two processes.

\section{Branchial arches}

The branchial arch consists of the basibranchial, hypobranchial, ceratobranchial, epibranchial, and infrapharyngobranchials (Fig. 6). The numbers of unpaired basibranchial are three that the anterior part of the basibranchial-3 is overlapped on the end of the basibranchial2. There are three hypobranchials in branchial arch which, the second hypobranchial is attached to the first basibranchial anteriorly. Four epibranchial are present, which the epibranchial-4 has a plate-like protrusion ventrally. The ceratobranchials are the largest elements of branchial arch, that fifth of them modified as pharyngeal teeth. Also, two pair of infrapharyngobranchials is present.

\section{Hyoid arch}

The hyoid arch includes the unpaired urohyal, and basihyal; paired hypohyal, ceratohyal, epihyal, and interhyal; and three pairs of branchiostegal (Fig. 7). The epihyal 
is subtriangular and bears a depression dorsally for connected to the small, rodshaped interhyal bone. Also, interhyal

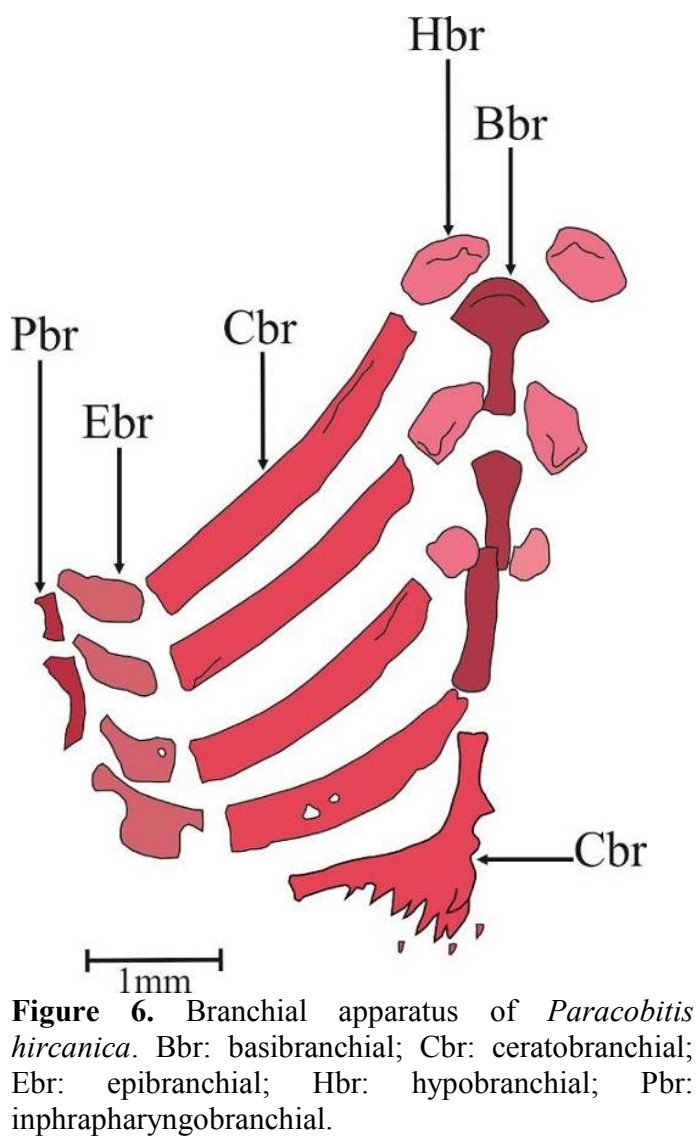

connected to the hyomandibular and symplectic dorsally. The paired ventral and dorsal hypohyal are tightly connected together. The ceratohyal is the largest bone in this collection which is situated between the hypohyal and epihyal bones. The first and second branchiostegal are positioned, respectively, in the middle of the ceratohyal and at the junction of the ceratohyal and epihyal. The third branchiostegal is also positioned in the middle of the epihyal. Also, these bones extended to the dorsal margin of subopercle. The urohyal is narrow and bears two ventral and dorsal parts. The dorsal part is blade-like and perpendicular to the ventral part. The basihyal is a Tshaped bone with a depression anteriorly.

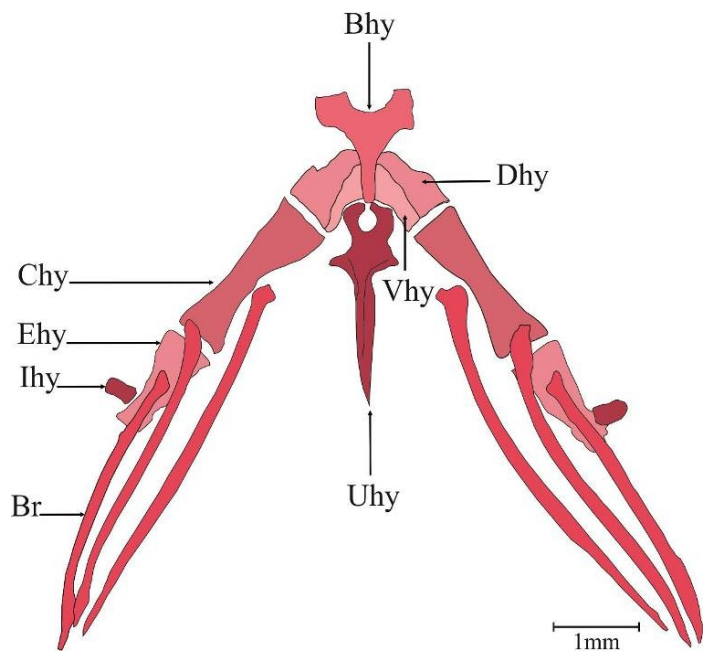

Figure 7. Hyoid arch of Paracobitis hircanica. Bhy: basihyal; Br: branchiostegale; Chy: ceratohyale; Dhy and Vhy: dorsal and ventral hypohyal; Epi: epihyal; Ihy: interhyal; Uhy: urohyal; Uhye: urohyal extra.

\section{Pectoral girdle}

The pectoral girdle includes the cleithrum, coracoid, mesocoracoid, scapula, supracleithrum, posttemporal, supratemporal, and radials (Fig. 8). The supratemporal is small and located in the anterior margin of the posttemporal. The supracleithrum is a flattened bone and connected to the cleithrum dorsolaterally. The posttemporal is thin and long, which located between the supracleithrum and supratemporal. Moreover, the posttemporal is connected to the epiotic from anterior process that, through this bone, the pectoral girdle is connected to the neurocranium.. The cleithrum is the largest element of the pectoral girdle that is connected to the coracoid through mesocoracoid lateromedially and to the 


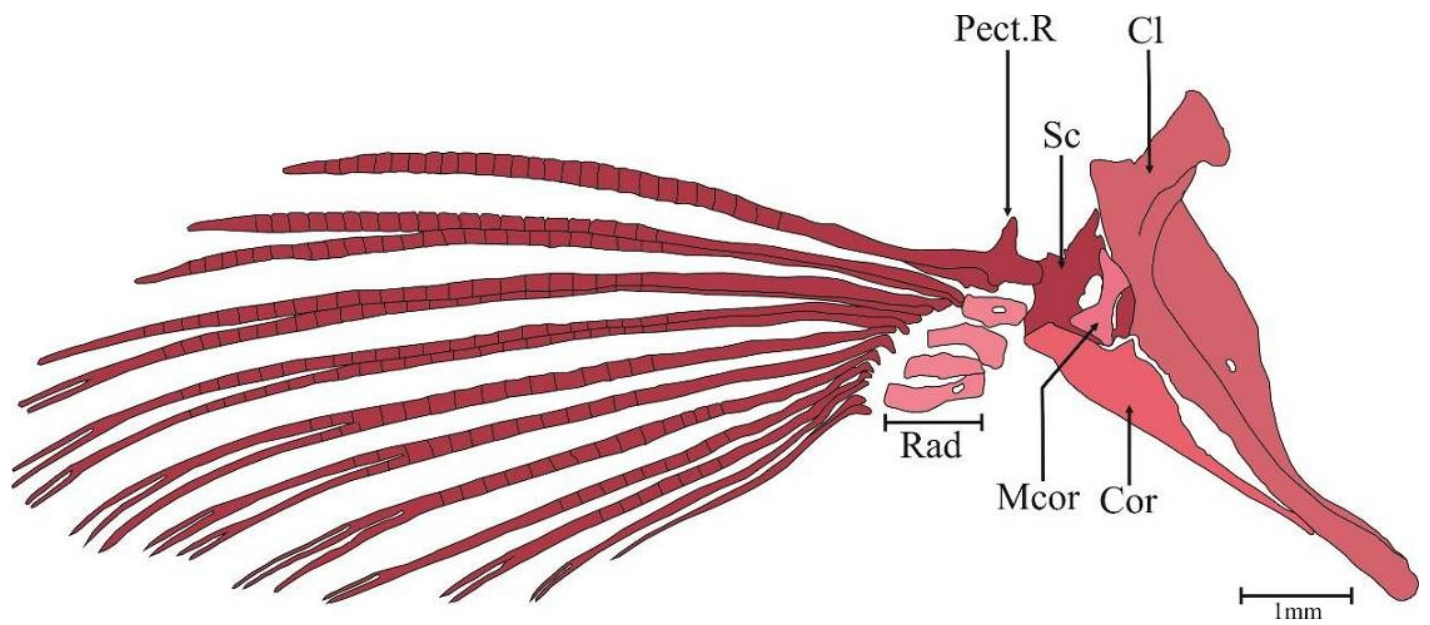

Figure 8. Pectoral girdle of Paracobitis hircanica. Cl: cleitherum; Cor: coracoid; Mcor: mesocoracoid; Rad: ossified pectoral radial; Sc: scapula.

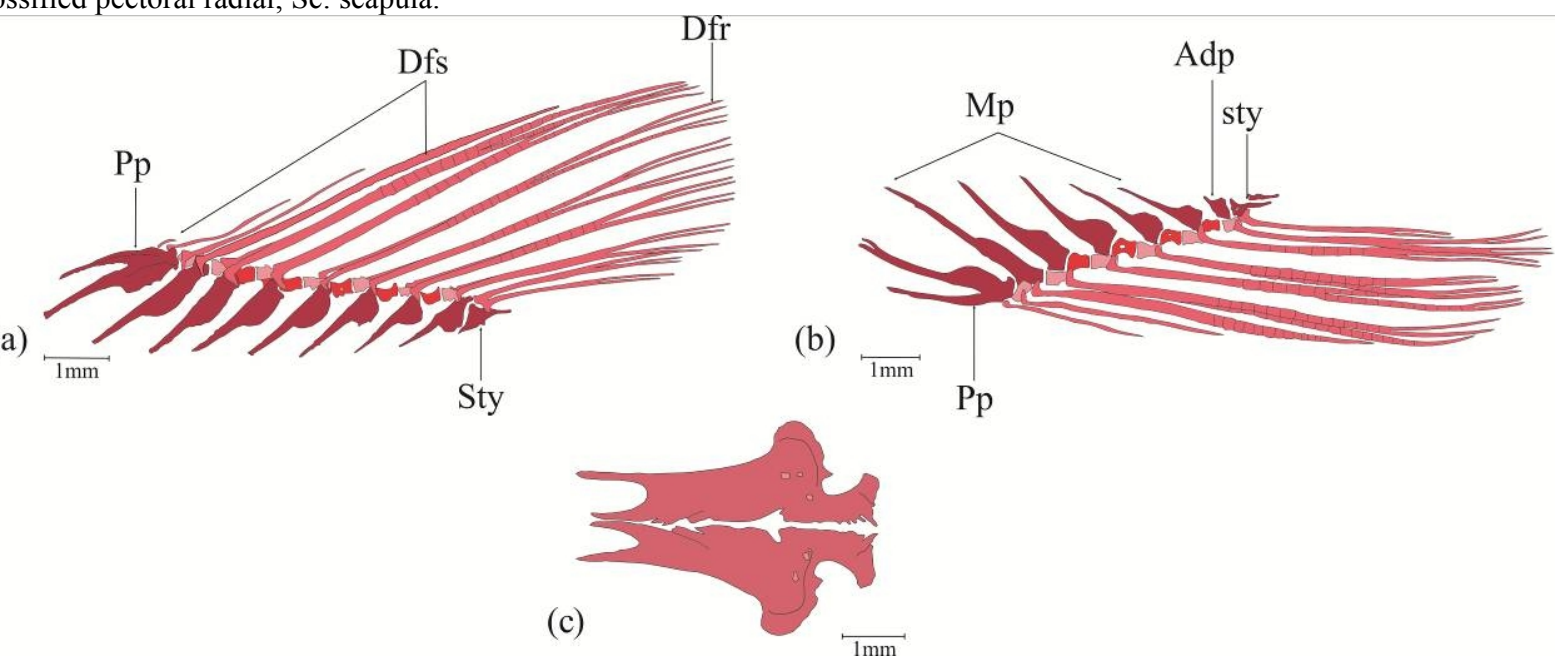

Figure 9. Dorsal fin (a), anal fin (b) and Pelvic girdle (c) of Paracobitis hircanica. Adp: anal distal pterygiophore; Dfr: dorsal fin rays; Dfs: dorsal fin spin; Mp: mesial pterygiophore; Pp: pterygiophore; Sty: stay.

supracleithrum dorsally.. Also, the anterior parts of the cleithrum and coracoid are connected to each other. In the coracoid, the anterior part is narrow, whereas its posterior part is wide. The scapula is trapezoidshaped and possesses a large opening (scapula foramen) which, is connected to the cleithrum and coracoid laterally. The pectoral girdle possesses four cylindrical radials that two first radials are narrow and thinner than the others. In pelvic fin, well developed styloid bone is present, and situated externally from the unbranched ray.

\section{Pelvic girdle}

The pelvic girdle is composed of the paired pelvic bones and radials (Fig. 9c). The paired pelvic bones are not connected to 
another skeleton, while enclosed by muscles of the abdomen. There are three radials (on each side of the bones) that are small and rounded positioning along the posterolateraledge of the ventral bone. The pelvic bones are directed horizontally that the anterior part is narrower than the posteriorly. Also, these bones have three processes including the anterior process (pubic process), the posteriolateral process (iliacus process) and the posterior process (ischiadicus process).

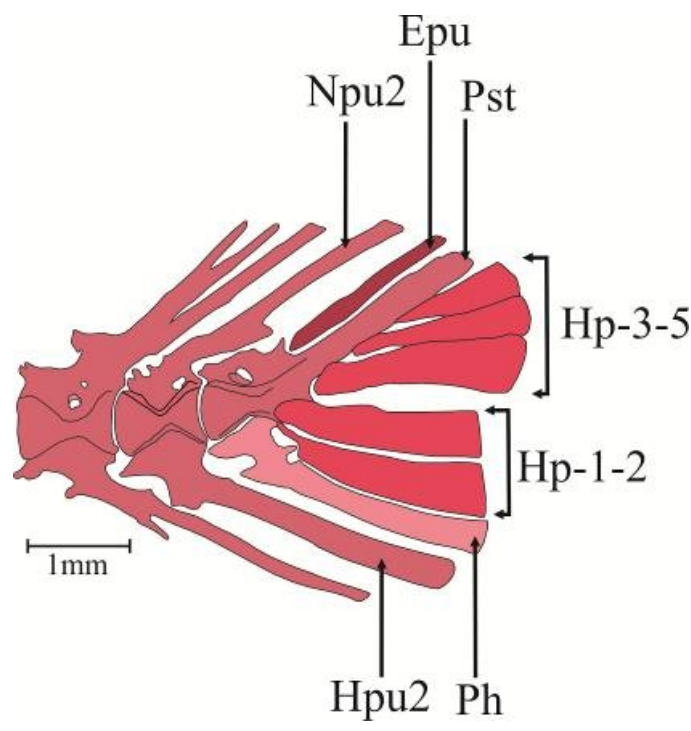

Figure 10. The caudal skeleton of Paracobitis hircanica. Epu: epural; Hp1-5: hypural plates; npu 2: neural processes of the second preural centrum; hpu_2: hemal processes of the second preural centrum; pst: pleurostile.

\section{Unpaired fins}

There are 8 pterygiophores in the dorsal fin, which the first pterygiophore is in the front of the tenth centrum (Fig. 9a). The number of unbranched rays is 4 and $7 \frac{1}{2}$ branched rays. The Anal fin is consisted of six pterygiophores and one stay (Fig. 9b). In addition, the first pterygiophore of anal fin is in the front of the twenty-third centrum. The number of unbranched anal fin rays is 3 and $5 \frac{1}{2}$ branched rays.

\section{Caudal skeleton}

The caudal skeleton comprises of 5 hypurals. The anterior section of the hypural-1 is wide with a pointed process posteriorly (Fig. 10). The hypural-1 is reaches to the edge of the terminal centrum and not connected to the parahypural ventrally. The parahypural is relatively long with two triangular processes in the posterior end and it is connected to the centrum. The hypural-2 and pleurostyl are tightly connected to the centrum. The hypurals 3, 4, and 5 are situated between pleurostile and hypural-2, which ends of these hypurals are connected to the ventral margin of the pleurostile. The epural is long, narrow and free, which it's connected to the pleurostile ventrally by connective tissue. The neural process of the three pleural of centrum is wide and bifurcated. Also, the haemal spine of three pleural is longer and bifurcated.

\section{Weberian apparatus and swim bladder capsule}

The weberian apparatus comprises of the claustrum, scaphium, intercalarium, and tripus (Fig. 11). The claustrum is oval-shape and situated on the scaphium ventrally. Also this small bone is connected to the supraneural-2 dorsally. The intercalarium is small and positioned between the scaphium and Y-shape tripus. The first centrum of the trunk has two lateral processes which connected to the pectoral girdlelateral by ligaments. This centrum does not participate in the formation of the bony capsule. The second and third centra of the trunk are fused. The second, third, and fourth centra 
(a)

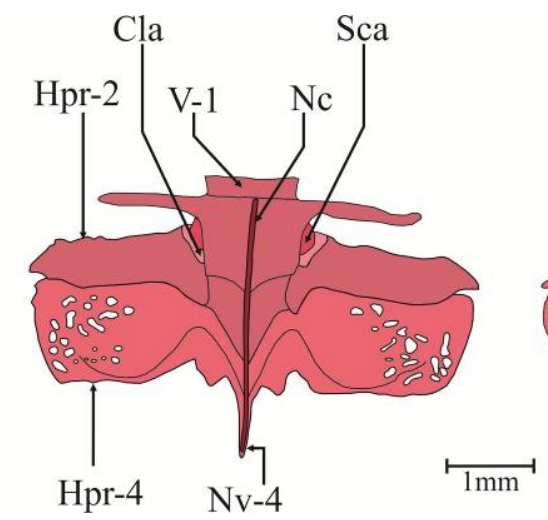

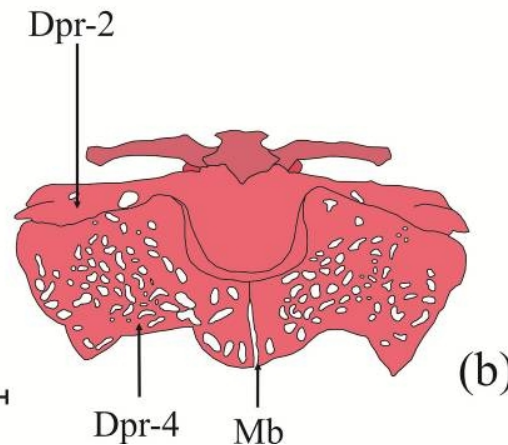

(b)

Figure 11. The swim bladder capsule of of Paracobitis hircanica; a) from above, b) from below; cla: claustrum; dpr-2 -4: descending processes of the second and fourth centra; hpr-2-4: horizontal processes of the second and fourth centra; mb: manubrium; nc: neural complex; nv-4: neural processes of the fourth centra; scp: scaphium; v1: first Centrum.

participate in the formation of bony capsule. The third centrum is situated between supraneural-2 and fourth centrum, anteriorly and posteriorly, respectively. The neural processes of the second and third centra are fused into a widened plate (complex neuralis). The parapophysis of forth centrum is modified and has similar processes as second centra which, is included in the structure of the posterior part of the bony capsule. Also, the neural process of the fourth centrum is attached to the posterior edge of the neural complex. The bony capsule is rectangular-shaped. In lateral side of bony capsule, two openings are observed that posterior one is larger. The surface of the bony capsule is alveolar, and the density of the alveolar is more in the ventral surface. The right and left lobes of the bony capsule are symmetrical, and they are connected by manubrium.

\section{Discussion}

The results of the present study provide the details of the skeletal system of Paracobitis hircanica. In $P$. hircanica, the junction of the lateral ethmoid is at the anterior margin of the orbitosphenoid such as, Oxynoemacheilus kiabii (Mafakheri et al., 2014), $O$. bergianus (Jalili and Eagderi, 2014), $O$. kermanshahensis (Mafakheri et al., 2015), Paraschistura nielseni (Azimi et al., 2015a) and P. cristata (Azimi et al., 2015b), while according to Prokofiev (2010) the lateral ethmoid of loaches is stationarily jointed with the supraethmoid-ethmoid.

There is no preethmoideum-I in $P$. hircanica like the $O$. kiabii (Mafakheri et al., 2014), O. bergianus (Jalili and Eagderi, 2014), O. kermanshahensis (Mafakheri et al., 2015), P. nielseni (Azimi et al., 2015a) and P. cristata (Azimi et al., 2015b), while this bone is present in species of the genera Lefua, Oreonectes, Yunnanilus, Eonemachilus, Micronoemacheilus, Hedinichthys, Orthrias, and Triplophysa (Prokofiev, 2010). Our observation, confirmed that there is no sesamoid ossification in $P$. hircanica, but in species $O$. kiabii (Mafakheri et al., 2014), O. bergianus (Jalili and Eagderi, 2014), O. kermanshahensis (Mafakheri et al., 2015) and P. cristata 
H. Azimi, H. Mousavi-Sabet and S. Eagderi/ Our Nature (2015), 13(1): 8-18.

(Azimi et al., 2015b) the sesamoid ossification is present. However, according to the Prokofiev $(2009,2010)$ sesamoid ossifications, as a rule, are present in genus Paracobitis and also in the species of Dzihunia amudarjensis and Oxynoemacheilus angorae.

Similar to the genera Metaschistura, Paraschistura, Oxynoemacheilus and Iskandaria, there is no bony bridge between parietal and pterotic in $P$. hircanica (Prokofiev, 2010).

According to Prokofiev (2010), generally in nemacheilid loaches the anterior hyomandibular facets are formed by the sphenotic and prootic, and that of the posterior one by sphenotic, prootic and pterotic, while in $P$. hircanica similar to the species O. kiabii (Mafakheri et al., 2014), $O$. bergianus (Jalili and Eagderi, 2014), $O$. kermanshahensis (Mafakheri et al., 2015), $P$. nielseni (Azimi et al., 2015a) and $P$. cristata (Azimi et al., 2015b), the facets are formed by the pterosphenoid, sphenotic and prootic in the anterior part, and sphenotic and pterotic in the posterior part. Prokofiev (2009), the pointed out that in the genus Paracobitis, retroarcticulare does not reach to the end of the dental, similar to $P$. hircanica. The basibranciale- 4 is absent in the $P$. hircanica similar to the other members of the genus Paracobitis (Prokofiev, 2009). However, in the species of O. kiabii (Mafakheri et al., 2014), O. bergianus (Jalili and Eagderi, 2014), $O$. kermanshahensis (Mafakheri et al., 2015) and P. nielseni (Azimi et al., 2015a) the basibranciale-4 is present. Prokofiev (2010) pointed out that the plate-like lateral protrusion is present on the epibranchial-4 in all species of Paracobitis which, this protrusion is found in the $P$. hircanica.
According to Prokofiev (2010), the coronomeckelian is connected to the base and dorsal edge of the coronoid process whereas, in $P$. hircanica like the species $O$. kiabii (Mafakheri et al., 2014), O. bergianus (Jalili and Eagderi, 2014), $O$. kermanshahensis (Mafakheri et al., 2015), P. nielseni (Azimi et al., 2015a) and P. cristata (Azimi et al., 2015b), this bone is situated in dorsal part of articular.

According to Prokofiev (2009) the hypurals number in the genus Paracobitis is six, but five hypurals are obvious in $P$. hircanica. However, six hypurals are observed in $O$. bergianus (Jalili and Eagderi, 2014). In P. hircanica, the epural is a free and long bone whereas, loss of the epural is usual for genera Lefua spp., Seminemacheilus, Afronemacheilus, and Hedinichthys grummorum (Prokofiev, 2010). Right and left lobes of the bony capsule are divided by manubrium in $P$. hircanica, like the species $O$. kiabii (Mafakheri et al., 2014), O. bergianus (Jalili and Eagderi, 2014), O. kermanshahensis (Mafakheri et al., 2015), P. nielseni (Azimi et al., 2015a) and $P$. cristata (Azimi et al., 2015 b) but, the manubrium is almost absent in the species Nun galilaeus, Afronemacheilus, Triplophysa fuxianensis, T. microps, and T. gracilis (Prokofiev, 2010).

As a result, Paracobitis hircanica is distinguished from other members of the subfamily Nemacheilinae and genus Paracobitis by having plate-like protrusion in epibranchial-4, no sesamoid ossifications, free and long epural, five hypurals, alveolar bony capsule and presence of the manubrium, no contact between retroarcticulare and dental, loss of preethmoideum-I and basibranciale-4. 
H. Azimi, H. Mousavi-Sabet and S. Eagderi/ Our Nature (2015), 13(1): 8-18.

\section{References}

Azimi, H., H. Mousavi-Sabet, S. Eagderi 2015a. Osteological characteristics of Paraschistura nielseni (Nalbant \& Bianco, 1998) (Cypriniformes: Nemacheilidae). Iranian Journal of Ichthyology 2(3): 155-164.

Azimi, H., H. Mousavi-Sabet, S. Eagderi, S. Vatandoust 2015b. Osteological characteristics of Turkmenian stone loach, Paraschistura cristata (Cypriniformes: Nemacheilidae). International Journal of Aquatic Biology 3(5): 290-300.

Bănărescu, P., T. Nalbant 1964. Süßwasserfische der Türkei. 2. Teil Cobitidae. Mitteilungen aus dem hamburgischen Zoologischen Museum und Institut 61: 159-201.

Bănărescu, P., T. Nalbant 1995. A generical classification of Nemacheilinae with description of two new genera (Teleostei: Cypriniformes: Cobitidae). Travaux du Muséum d'Histoire Naturelle Grigore Antipa, Bucurešti 35: 429-496.

Bleeker, P. 1863. Sur les genres de la famille des Cobitioïdes. Nederlands Tijdschrift van Dierkunde 1: 361-368.

Coad, B.W. 2014. Fresh water fishes of Iran. Retrieved from $h t t p: / / w w w . b r i a n c o a d . c o m$.

Freyhof, J., H.R. Esmaeili, G. Sayyadzadeh and M. Geiger 2014. Review of the crested loaches of the genus Paracobitis from Iran and Iraq with the description of four new species (Teleostei: Nemacheilidae). Ichthyol Explor Freshwaters 25: 11-38.

Jalili, P. and S. Eagderi 2014. Cephalic osteology of Safidrud stone loach Oxynoemacheilus bergianus. Iranian Journal of Biology 27(2).

Jouladeh-Roudbar, A., S. Vatandoust, S. Eagderi, S. Jafari-Kenari and H. Mousavi-Sabet 2015. Freshwater fishes of Iran; an updated checklist. AACL Bioflux 8(6): 855-909.

Kottelat, M. 2012. Conspectus cobitidum: an inventory of the loaches of the world (Teleostei: Cypriniformes: Cobitoidei). The Raffles Bulletin of Zoology 26: 1-199.

Min, R., X.Y. Chen and J.X. Yang 2010. Paracobitis nanpanjiangensis, a new loach (Balitoridae: Nemacheilinae) from Yunnan, China. Environmental Biology of Fishes 87: 199-204.

Mafakheri, P., S. Eagderi, H. Farahmand, H. Mousavi-Sabet 2014. Osteological structure of Kiabi loach, Oxynoemacheilus kiabii
(Actinopterygii: Nemacheilidae). Iran. J. Ichthyol 1(3): 197-205.

Mafakheri, P., S. Eagderi, H. Farahmand, H. Mousavi-Sabet 2015 Descriptive osteology of Oxynoemacheilus kermanshahensis (Bănărescu and Nalbant, 1966) (Cypriniformes, Nemacheilidae). Croatian Journal of Fisheries 73:115-123.

Mousavi-Sabet, H., A. Gharaei, A. Nasrollahzade, A. Habibi and S. Eagderi 2014. Redescription of Paracobitis rhadinaea (Regan, 1906) from Sistan Basin, Iran (Teleostei: Nemacheiliidae) International Journal of Aquatic Biology 2(5): 286291.

Mousavi-Sabet, H., G. Sayyadzadeh, H.R. Esmaeili, S. Eagderi, R. Patimar and J. Freyhof 2015. Paracobitis hircanica, a new crested loach from southern Caspian Sea basin (Teleostei: Nemacheilidae). Ichthyol. Explor. Freshwaters, Accepted.

Nalbant, T. and P. Bianco 1998. The loaches of Iran and adjacent regions with description of six new species (Cobitoidea). Italian Journal of Zoology 65 : 109-123.

Nelson J.S. 2006. Fishes of the world. John Wiley and Sons Inc. New York.

Nguyen, V.H. 2005. Freshwater fishes of Vietnam. v. 2: $760 \mathrm{p}$.

Prokofiev, A.M. 2009. Problems of the classification and phylogeny of Nemacheiline loaches of the group lacking the preethmoid I (Cypriniformes: Balitoridae: Nemacheilinae). Journal of Ichthyology 49: 874-898.

Prokofiev, A.M. 2010. Morphological classification of loaches (Nemacheilinae). Journal of Ichthyology 50: 827-913.

Sawada, Y. 1982. Phylogeny and zoogeography of the superfamily Cobitoidea (Cyprinoidei, Cypriniformes). Memoirs of the Faculty of Fisheries of Hokkaido University 28: 65-223.

Taylor, W.R and G.C. Van Dyke 1985. Revised procedures for staining and clearing small fishes and other vertebrates for bone and cartilage study. Cybium 9: 107-119.

Vatandoust, S., A. Joladeh Roudbar and H. MousaviSabet 2014. First record of the loach fish Paracobitis cf. hircanica in the Kavir basin, northern Iran. International Journal of Aquatic Biology 2(1): 27-28. 